\title{
A Process and Outcome Evaluation of a One-Semester Faculty Learning Community: How Universities Can Help Faculty Implement High Impact Practices
}

\author{
Susan D. Einbinder, MS, PhD \\ Associate Professor, Social Work Department, College of Health, Human Services \\ and Nursing \\ California State University Dominguez Hills
}

\begin{abstract}
This process and outcome qualitative study describes and critically assesses the experiences of the faculty who participated in the one-semester FLC addressing CLTs through a content analysis of individual narratives completed at the end and ten months after the FLC ended. The existence and contributions of four prerequisites for successful collaboration (Einbinder, Robertson, Garcia, Vuckovic \& Patti, 2000) are introduced to explain this FLC's success and then extended to suggest how future FLC initiatives can expand and improve on these accomplishments.
\end{abstract}

Collaborative learning techniques (CLTs) and Faculty Learning Communities (FLCs) are two of ten high-impact practices (HIPs) ${ }^{1}$ touted as relatively inexpensive and proven ways to improve the quality of higher education (Bonet \& Walters, 2016; Brownell \& Swaner, 2010; Ganeshi \& Smith, 2017; Kilgo, Sheets, \& Pascarella, 2015; Kuh, 2008). In the study reported here, collaborative learning techniques (CLTs) refer to instructor-designed, in-class group activities that require students to work together collaboratively and are intended to facilitate improved critical thinking skills and increased knowledge acquisition (Barkely, Major, \& Cross, 2013).

U.S. and Canadian institutes of higher education have been introducing FLCs in the U.S. at a fast pace (Hegler, 2004; Furco, \& Moely, 2012). In 2004, there were an estimated 300 FLCs (Beach \& Cox, 2009, as cited in Desrocher, 2011). By 2012, more than 800 FLCs were documented (Jessup-Anger, 2015). In spring 2015, FLCs were introduced at California State University Dominguez Hills (CSUDH), a public university educating 10,000 diverse undergraduate and 3,000 graduate students in Los Angeles County, California. These FLCs were part of a multi-pronged, broad-based initiative to increase retention and graduation rates introduced by the Provost who had joined the campus in January 2014.

Faculty at all ranks were invited to apply for one of nine scheduled FLCs, each addressing a different topic. Topics addressed included: (1) writing-intensive courses, (2) collaborative learning techniques, (3) undergraduate research, (4) diversity/global learning, (5) service-learning, (6) internships, (7) capstone courses and projects, (8) local history as pedagogy: The Watts rebellion; and (9) Affordable Learning Solutions

1 The other HIPS are first-year seminars and experiences; common intellectual experiences (core curriculum); writing-intensive course; undergraduate research; diversity and global learning courses examining "difficult differences;" service- or community-based learning; internships; and capstone courses and projects (Kuh, 2008). 
$(\mathrm{CSUDH})^{2}$. Coordinated through the campus' Faculty Development Center, application review generated invitations to faculty to serve as participants. In each FLC, two faculty were invited to serve as co-facilitators and provided with 2 hours of training in advance. A total of 90 full-time faculty took part in these FLCs (CSUDH Academic Affairs, personal communication, 2017).

This process and outcome qualitative study describes and critically assesses the experiences of the faculty who participated in the one-semester FLC addressing CLTs through a content analysis of individual narratives completed at the end and ten months after the FLC ended. The existence and contributions of four prerequisites for successful collaboration (Einbinder, Robertson, Garcia, Vuckovic, \& Patti, 2000) are introduced to explain this FLC's success and then extended to suggest how future FLC initiatives can expand and improve on these accomplishments.

\section{What are Faculty Learning Communities?}

An FLC is, essentially, a study group whose members engage in conscious, self-directed and collaborative learning to master specific knowledge and skills (Sicat et al., 2014). FLCs usually target improved student learning by enhancing teaching quality (Hubball, Clarke, \& Beach, 2004, p. 88). Comprised of a small number of faculty or faculty and students, FLCs can operate for one semester or longer. They can be topic-based, addressing a specific teaching approach or skill, or they can be cohortbased, including only faculty at the same rank (Bishop-Clark, Dietz, \& Cox, 2014). Membership can be interdisciplinary, but FLCs are most commonly comprised of participants from the same discipline or profession (Sicat et al., 2014). FLCs have been recommended for mid-career faculty interested in regenerating their research and teaching interests (Blaisdell \& Cox, 2004; "How to Recruit Faculty to Learning Communities," 2006; "Look to Midcarrer Faculty for Learning Communities," 2006). At one campus, tenure-track faculty formed cohort-based FLCs. Members collectively designed and conducted a research project that generated a publication and simultaneously integrated components of the research project into their teaching in the classroom. These participants concluded that the FLC was an effective way to improve their teaching and increase their scholarship (Hershberger, Cesarini, Chao, Mara, Rajaei, \& Madigan, 2005).

\section{Effectiveness of Faculty Learning Communities}

Research evaluating whether and how well FLCs improve student learning outcomes and/or increase retention and graduation rates is limited but growing. The majority of published studies have small samples, are non-experimental, rely on faculty perceptions and beliefs as indicators, and only collect data a few times over a short period of time, but they consistently report that FLCs improve student learning

2 Affordable Learning Solutions is an initiative enabling faculty to reduce the costs of books and required readings for students by using free, open-source, and reduced-cost sources (California State University, Office of the Chancellor, 2012). 
(Addis et al., 2013; Beery et al., 2011; Bishop-Clark et al., 2014; Desrochers, 2011; Hegler, 2004; Jackson, Stebleman \& Laanan, 2013; Sicat et al., 2013).

Continuous, ongoing assessment was noted as key for improving FLCs and necessary to generate support to institutionalize them and ensure their sustainability (Gray, 2000). Hubball et al. (2004) suggested assessing three broad areas: student learning indicators, FLC outcomes, and faculty learning measures. Summative and formative protocols have also been recommended (Hillard, 2015). Sicat et al. (2014) encouraged administrators to include FLC faculty in designing, implementing and carrying out protocols evaluating this work.

\section{Challenges of Improving Teaching through Faculty Learning Communities}

Universities have established robust reward systems encouraging faculty research, but few provide initiatives to enhance teaching quality. Baker et al. (2014) observed that research rewards and incentives detract from attention on teaching quality, enabling faculty and institutions to ignore inferior and ineffective instruction and instructors. Simply demanding that faculty improve their teaching or mandating that everyone adopt high impact practices cannot be done without a major cultural change (Addis et al., 2013). Such changes would require significant modifications to employment contracts, tenure and promotion standards and myriad other considerations.

While research has increasingly become a collaborative endeavor, teaching remains a predominately individual and isolated activity (Sirum, Madigan, \& Kilonsky, 2009). There are few external rewards to mastering new pedagogies, which take time to learn. Changing one's teaching style can complicate departmental teaching assignments, contradict accreditation requirements, and confuse students and colleagues, especially if more than one version of the class is offered by two different faculty who teach the same content in very different ways. And, of course, time spent on teaching takes away from time spent on research or other pursuits.

Faculty have reported that FLC participation is time-consuming, adding to their already demanding workloads (Beery et al., 2011). Fifty-five percent of faculty who participated in a 3-year, federally funded, multi-campus FLC initiative to integrate community internship experiences into their classes reported that they were unable to do so; the most common reasons they offered were collegial or faculty resistance and insufficient funds (Furco \& Moely, 2012).

FLCs made up of faculty who volunteered to participate offer a way to incrementally revise expectations and requirements of instruction. Faculty who participated in FLCs reported improved job satisfaction (Jackson et al., 2013), increased pedagogical and interdisciplinary knowledge (Hegler, 2004), enhanced collaboration abilities (Sicat et al., 2014), and positive mentoring experiences (Beery et al., 2011). They also appreciated opportunities to collegially share and build on their teaching knowledge and skills in a "safe place" (Furco \& Moely, 2012). Faculty interest in interdisciplinary collaboration, the heart of an FLC, motivated administrators at the City University of New York (CUNY) to create integrated, coordinating structures combining teaching and research. These structures have enabled the institution to entice internationally esteemed and far better paid faculty to leave tenured positions at 
Ivy League and other private universities and join the CUNY faculty (Robinson, 2014). And CUNY successfully courted these academic superstars while addressing complaints of dirty classrooms, unhygienic bathrooms and rodent infestations on the campus (Ahmad, 2016).

\section{Recommendations for Successfully Implementing FLCs}

Integrating FLCs into a university's mission has been noted as a positive factor in their successful implementation (Boose \& Hutchings, 2016) and as a way to enable sustainability (Gray, 2000). A framework for assessing FLC success comes from a study that identified four prerequisites for successful collaboration by professionals at California's county-level child welfare agencies: Incentives, willingness, ability and commitment (Einbinder et al., 2000).

Incentives. Incentives refer to institutional and individual motivations to work collaboratively, including access to resources. These can include tangible rewards (money), knowledge acquisition, and opportunities to build collegial relationships. Based on the experiences of participating faculty in a 3-year, federally funded, eightcampus FLC initiative facilitating service learning, concrete incentives should replace, rather than add to, existing workloads (Furco \& Moely, 2012). A quasi-experimental study of FLCs improving science instruction reported that these incentives be made clear to participating faculty to encourage participation (Addis, et al. 2013).

Willingness. Willingness describes the conditions and environment needed for trust and respect to grow among and between collaborating participants, creating a "safe space" for developing shared values through open, reciprocal, and equitable interactions. The overall goal of the FLC, as presented by administrators, must honor faculty values in order to succeed in establishing willingness by faculty (Furco \& Moely, 2012).

Ability. Ability describes the knowledge, skills and expertise to collaborate: Collaboration is a skill often taken for granted and just as frequently unfamiliar to novice practitioners. Learning while doing is common (Hegler, 2004), but success is more likely when FLCs have trained, seasoned facilitators (Beery et al., 2011; Desrouchers, 2011; Ortquist-Ahrens \& Torosyan, 2009; Sicat et al., 2014). Ensuring participant access to FLC research has also been noted as a factor (Beery et al., 2011; Desrochers, 2011). Having a free-standing, independent Faculty Development Center on campus that is sufficiently staffed and funded to coordinate campus-wide events and activities is another example, along with library subscriptions to the full range of academic journals with articles investigating the effectiveness of high impact practices for faculty to access as desired.

Capacity. Capacity refers to administrative mechanisms and arrangements that facilitate successful collaboration, seen as essential elements for FLC success (Furco \& Moely, 2012). One example is administrative commitment to ongoing support (Furco \& Moely, 2012). Including FLC faculty in designing and implementing protocols to evaluate FLCs (Boose \& Hutchings, 2013; Sicat et al., 2014) and opportunities for FLC faculty to generate publications and presentations about their work (Sicat et al., 2014) are also capacity-builders.

The CSUDH faculty in this CLT FLC had no experience working collaboratively with each other, participating in an FLC, or using CLTs in their 
teaching. This process and outcome evaluation was created for three reasons: (1) to show how these faculty managed this experience; (2) to evaluate its effectiveness; and (3) to recommend how to improve on what was done to increase the likelihood that other campuses instituting FLCs can better facilitate supporting faculty interested in improving their teaching to increase student learning.

\section{Methodology}

Design. A qualitative, longitudinal research design was used in this evaluation. The FLC met five Friday mornings throughout the semester. Participants independently wrote narratives twice: After the last FLC session and 10 months later.

Participants. Ten faculty attended the first FLC meeting in spring 2014; two of the participants also served as c-facilitators and had completed a two-hour pretraining. None of the faculty had any experience participating in an FLC.

One faculty member withdrew after that session without explanation. The five men and four women in this FLC were, collectively, responsible for over 100 years of undergraduate and graduate instruction at CSUDH and on other campuses. Three identified as Latino, one as Indian, and five as Caucasian. Faculty who attended all five sessions, submitted a revised syllabus, and implemented a CLT in it in fall 2015 received \$1,000. A co-facilitating FLC member left CSUDH in the summer of 2015, after the FLC ended for reasons unrelated to the FLC or this study.

An interdisciplinary, mixed-rank group, participants included one tenuretrack first-year Assistant Professor, one part-time Lecturer, three full-time Lecturers, two tenured Associate Professors and two tenured Professors. Graduate and undergraduate courses targeted for modification were in accounting, economics, finance and business, foreign language, humanities, negotiation, public administration, public policy, and social work. The co-facilitators were full-time Lecturers who had completed a 2-hour training to prepare them for this work.

Materials and procedures. CSUDH IRB approval was obtained before beginning this study. After the last meeting, faculty were asked to write about what it was like for them to participate in this FLC with no specific suggestions or advice on content or length. Ten months later, faculty were sent nine open-ended questions and asked to send their replies to the author via email. They were asked if they had implemented collaborative learning techniques, how they evaluated this work, whether it improved their teaching as well as students' critical thinking skills and learning outcomes, and to identify additional resources that would enable them to continue this work (see Table 1 on p. 49).

Nine of the participants completed the post-FLC narratives. Eight of these nine participants completed the 10-month post-participation questions.

Data analysis. A conventional content analysis (Hsieh \& Shannon, 2005) was conducted on the unstructured post-participation narratives. Each narrative was read one-at-a-time to get an overall impression of each participant's experience. They were re-read a few more times to find latent content not stated directly but implied, as interpreted by the researcher. This analysis is supplemented with details of the activities completed and issues addressed in each of the five FLC sessions to generate a "picture" of this experience. 
The 10-month post participation narratives were analyzed using summative content analysis (Hsieh \& Shannon, 2005). Responses to the open-ended questions were classified (i.e., yes or no) and counted, one question at a time. For example, the participants were asked how they felt about collaborative learning techniques. The number of participants who were enthusiastic, ambivalent or skeptical were tallied. Then the manner in which they described these feelings was re-read a few times in order to assess latent content, or the underlying message of the comment that might not be included in the explicit or manifest responses. This process was repeated for each question.

Validity and reliability. Assessing validity and reliability in qualitative research is difficult. The criteria of authenticity and credibility (Lincoln \& Guba, 1985), respectively, are roughly comparable tools to assess validity and internal validity in qualitative studies. Since the author was also a participant in the FLC, contributed an individual narrative, and interpreted these findings, these criteria are important to address.

Authenticity assesses the degree to which the participant experiences were faithfully described. It is roughly comparable to validity in quantitative research. Credibility evaluates whether the study findings seem believable and truthful. It is roughly comparable to internal validity in quantitative research. One way to test for authenticity and credibility is to ask study participants to read the manuscript and give feedback regarding what they think of the researcher's interpretation of the data, called "member-checking" (Lincoln \& Guba, 1985). All of the FLC participants received an earlier version of this manuscript that they were asked to read carefully and send the researcher any and all questions, concerns or criticisms about it, including the interpretation of the data. None challenged any part of the manuscript. While this response may be because it was not read comprehensively, it is more likely that they found the description authentic and credible.

One of the characteristics of qualitative research is its intentional subjectivity; its purpose is to capture individual, eccentric information that is drowned out in quantitative studies. Qualitative study findings are not often generalizable. In this study, the faculty who participated in the CLT FLC likely held similar attitudes, beliefs and opinions as those of the 81 additional CSUDH full-time faculty who took part in this initiative. Whether and how many faculty on other campuses feel the same way is unclear. But concerns about increasing retention and graduation rates are common at most public and many private institutions of higher education in the U.S., as are initiatives implemented to address them, suggesting that this study's findings may be helpful beyond the CSUDH campus.

\section{Findings}

Findings from the conventional content analysis are presented first. These depict faculty attitudes and opinions about the CLTs and how they experienced participating in the FLC. The summative content analysis of 10-month-postparticipation narratives follows. This content portrays participant experiences implementing and evaluating the CLTs they designed during the FLC, as well as their thoughts about both. Direct quotes are cited by the participant's number and the page number on the narrative each person submitted. 


\section{Process Evaluation}

Unbeknownst to each other, every participant was skeptical about the effectiveness of CLTs. A few pointed out that the CLTs were foreign to them and antithetical to their own "traditional" learning. One suggested that CLTs offered a way for students to evade learning:

The learning process for me was always to read the textbook chapter before coming to class, attend lecture, which was in many cases a mechanical repeat of the textbook chapter, and to work the homework examples on my own time and in my house. I used to work full time then and attend college full time also, so group projects were a waste of time and highly inefficient. I believed that some people truly enjoy to work in groups because they liked to socialize and chat about things unrelated to academics or because they do not want or do not know how to complete the assignment on their own (5, p. 1).

Another participant confessed a deep dislike of collaborative learning itself, a result of three failed collaborative assignments in graduate school. Even though many participants disclosed their (mostly negative) feelings about CLT, none had mentioned them in the FLC sessions.

In the same vein, most of the faculty, including the co-facilitators, were also nervous about what they were supposed to do during each FLC session and how the FLC process functioned. This sentiment, too, was held by most participants but never shared among them or discussed in the FLC sessions. A co-facilitator's comment reflects this confusion: "I am collaboratively facilitating an FLC - which is itself a form of collaboration - on collaborative assignments and projects" $(7$, p. 1).

These unshared misgivings raise a question: Why did these faculty voluntarily participate in this unknown process, given their ambivalence and uncertainty about FLCs and CLTs?

In their narratives, participants described their strong commitment to teaching excellence, a treasured value perceived as a job requirement. The FLC participants dedicated themselves to improving the quality of their instruction out of this sense of obligation. As one participant put it: "I have always been open to the possibility that there might be a better way to teach and prepare students than the way I learned in college and later applied to my own students" $(5, \mathrm{p} .1)$. They also respected fellow colleagues who shared these values, and this mutual respect permeated FLC interactions. Teaching was discussed with a reverence more commonly reserved for scholarly research. These shared beliefs likely helped the FLC succeed.

Confusion in the first three sessions. The first three FLC sessions were experienced as confusing and unclear $^{3}$. Armed with a 2-hour pre-training, the cofacilitators struggled to guide the group, even on a supposedly simple task of getting

3 This confusion and insecurity led the author to conduct a comprehensive literature search that inspired this study. Publications describing the FLC process and studies investigating the effectiveness of collaborative teaching techniques were located and posted on the FLC's Blackboard site, to share with all of the CLT FLC participants. 
faculty participants to collaborate on determining what to do in each session. After deferring to requests to devote FLC session time to a non-FLC activity, one cofacilitator said:

Many members in the group seem to be interested in what strikes me... as basic LMS/Blackboard training...CSUDH offers Blackboard workshops every term. Yet, not until they committing to meeting for five Fridays with a task to deliver...have some members actually wanted to know what tools are available and how to use them. $(7$, p. 1)

While the organizational website that the co-facilitators arranged for FLC participant use was viewed as very helpful, it did little to defray confusion over the FLC process. At its inception, it contained meeting agenda, publications, and "files" for participants to submit their "before and after" syllabi.

At the third session, an article by Sirum et al. (2009) that specified concrete activities for each FLC session was reviewed by participants, and agreement was reached to implement some of them in the remaining two FLC sessions. This step created a transformation in the CLT FLC.

Transformation. At the fourth meeting, FLC members worked in teams to practice some of the 31 collaborative learning techniques in Collaborative Learning Techniques (Barkley, Major, \& Cross, 2014), a book purchased by the Faculty Development Center and given to each FLC participant (without charge). In the fifth and last session, FLC participants brainstormed, in groups of two, how to salvage a collaborative learning technique imperiled by a "difficult" student, using vignettes provided by the co-facilitators. Finally, each participant demonstrated one of the CLTs that had been modified for implementation to the group and received feedback after the presentation was completed.

This transformation was noted in participant narratives. One identified the change "...we gathered momentum when we experienced actual collaborative skills ourselves and discussed how to resolve conflicts with difficult students (6, p. 1)."

The opportunity to brainstorm how to deal with a difficult student and the chance to practice implementing a CLT generated confidence and satisfaction among the participants, as noted "...participants focused on understanding and practicing different types of collaborative learning techniques to enable us to successfully revise syllabi and generate deliverables (5, p. 2)."

Immediate post-participation assessment: Mixed views. All of the participants said that they enjoyed taking part in the FLC, as their comments show:

"I am learning a lot from my participation in the FLC and plan to use that knowledge to apply it to one of my courses" $(5, \mathrm{p} .1)$.

“... a positive learning and useful experience..." (2, p. 1).

"I greatly enjoyed the interacting and sharing information among faculty...it was very significant in continually improving an instructor's ability to teach" (1, p. 1).

I did not think I would learn anything new, but was pleasantly surprised ... I like the idea of incorporating games and competitions 
among groups in my classes, and it will make learning a very fun experience for my students. $(2$, p. 1$)$

The snacks that different FLC members brought to share to each of the five meetings were also applauded. One said that the snacks enhanced the FLC's learning environment, but another said, "While it was appreciated that members took turns bringing food for everyone, it was unsurprising that the only ones who did this were the women. The men never volunteered to bring food" $(8$, p. 2).

There were also negative comments. Many participants felt that the FLC ending was abrupt, and that the FLC's work was incomplete. One reported feeling unprepared to implement the CLTs: "Another major concern is how to measure the effectiveness of group assignments versus individual assignments" (6, p. 1).

Another participant shared disappointment:

Although I asked a few times that we agree to extend our FLC into the fall semester and that we meet again before the onset of the fall semester to discuss introducing a standardized assessment process across all of our courses, one of our co-facilitators left CSUDH and the enterprise was abandoned. $(8$, p. 3$)$

CSUDH Faculty Development Center. The Director of the Faculty Learning Center visited briefly in the first and last FLC sessions to solicit data from the participating FLC faculty, who were asked to complete a standardized survey. No further information was provided about what, if anything, was done with that data.

\section{Outcome Evaluation}

Table 1 presents responses to eight of the nine open-ended questions in the 10-month-post-participation narrative. The ninth, identifying resources, is addressed separately.

Seven of the eight participants reported that they had successfully implemented collaborative teaching techniques in the fall semester. One intended to do so in the next academic year, when the course modified with collaborative teaching techniques was next offered.

The participants who implemented their FLC work also evaluated it. Evaluation protocols were varied. One used a rigorous experimental design (randomly assigning students to participating in the collaborative learning technique or not) to gather feedback from students. These findings suggested that the CLTs were effective in terms of student learning, but the sample was too small to test for statistically significant differences between the groups. Pre-/post-tests and multiple assessments during the semester, using standardized surveys, were also used; all showed that the collaborative learning techniques had been effective at improving student learning and critical thinking. The two participants who relied on informal feedback solicited from their students to conclude that their work was effective, and 
one more who relied on student feedback on the mandatory course evaluation administered by the university, also claimed that their work was effective based on this data.

Table 1

10-month Post-Participation Responses: Summative Content Analysis Findings

Open-ended question

(1) Did you integrate and implement collaborative learning techniques from our FLC into your fall teaching? How did it work out?

(2) Please describe whether and how you chose to evaluate these modifications, and, if you did, how you did so and what you learned.

(3) Please describe whether and how you informed your students of your use of these high-impact practices (or if you did not, and why).

(4) Do you plan to continue to integrate collaborative learning techniques into your teaching?

(5) Did you share your work with collaborative learning techniques with faculty in your department?

(6) Do you think that collaborative teaching techniques improved your students' ability to learn and think critically?

(7) Did it make you a better teacher?

(8) How much did the FLC prepare you to integrate collaborative teaching techniques into your teaching?

\section{Responses}

- Yes (n=7); all had positive experiences

- $\quad$ No (n=1); One participant planned to implement next term

- Yes $(n=8)$

o Informal discussions with students $(\mathrm{n}=2)$

o Pre/post-standardized surveys $(\mathrm{n}=1)$

o Multiple measures during semester, including pre/post surveys $(\mathrm{n}=2)$

o Perceived Teaching Effectiveness (student evaluations) $(\mathrm{n}=1)$

o Have not designed yet $(n=1)$

- $\quad$ No $(n=4)$ - they knew already; would impair evaluation; no need to inform

- Yes (n=3) - Written into syllabus; important for students to know what is going on

- Have not decided $(\mathrm{n}=1)$

- Yes $(n=8)$

- $\quad$ No $(n=4)$ - not prepared; lack of interest/support within department

- Yes $(n=4)$ - informally; 2 FLC participants were in the same department

- Not sure/No ( $n=3)$ - no empirical evidence

- Yes $(n=5)$ - grades higher; students said it helped them prepare for exams; applied to real-life problems

- No/Maybe $(\mathrm{n}=3)$ - less controlling \& students liked class better; more effective teaching; students had fun

- Yes $(n=5)$ - shifted role to facilitator; more engaged; thinks it will

- Would not have implemented collaborative teaching techniques without participating in FLC $(n=6)$; significantly; most effective way; helpful; forced the focus 
Four participants were convinced that this experience made them better teachers and improved student learning and critical thinking skills. Three participants were not so sanguine. Two pointed out that their empirical evidence was not sufficient to conclude this result. All three admitted that their students seemed to enjoy - and had more fun - in the classes in which they had implemented collaborative learning techniques.

All of the CLT FLC participants intended to continue and expand integrating collaborative learning techniques in their teaching. The FLC itself was credited as the best forum to learn how to do this. Six stated that they never would have changed their teaching by designing and implementing CLTs in their class without the FLC, which functioned as a safe, supportive place to learn and practice with their colleagues.

\section{Suggestions from Participating Faculty}

The majority of recommendations made in the 10-month-post-participation narratives identified resources and issues that the university could provide, as Table 2 shows on $\mathrm{p} 51$.

All of the participants wanted more: More training; more time in this FLC, more FLCs, and more support for FLCs. Three participants asked for additional training in CLTs and other high-impact practices in online and hybrid classes. Two participants wanted this FLC reconvened and run for another 2 consecutive semesters. Another suggested an 18-month FLC to maximize its effectiveness. In this model, participating faculty would study and plan their collaborative learning techniques in a spring semester. That fall, each instructor would implement their CLTs and gather data. Then, in the following spring semester, they would access help in analyzing and evaluating their work and generating conference presentations and scholarly publications.

Another participant recommended that the university ensure that every student had a cell phone, tablet or laptop to facilitate full participation in collaborative learning in their classes. One more suggested that senior administrators should require department chairs to support interdisciplinary collaborations like this FLC.

Providing funding to faculty to attend and present their research at high impact practices conferences, and sponsoring on-campus forums or workshops for faculty who had completed this FLC to share their experiences with campus colleagues were also suggested. Two participants noted that limited library holdings and subscriptions made it difficult to explore the effectiveness of high impact practices and asked that this be addressed.

\section{Conclusion and Recommendations}

This qualitative process and outcome study described the experiences of faculty who voluntarily took part in a one-semester FLC to learn how to implement CLTs in their classes at a state-funded, public university in Los Angeles County. It demonstrated that this FLC created conditions that built trusting relationships among and between the participants, generated conditions for learning and preparing to implement CLTs, and served as a campus mechanism for interested faculty to gain 
Table 2

Recommendations for Improving Support of Collaborative Learning Techniques

Student Access to Technology $(n=1)$

- Ensure that every student has a cell phone, tablet or laptop to use in class to enhance collaborative learning experiences

Extend this FLC's Lifespan/Institutionalize Formal FLC Structure ( $=5$ )

- Continuation of this FLC (1) since it was "very significant in continually improving an instructor's ability to effectively teach" (1)

- $\quad$ Formalize the FLC structure and make this FLC ongoing to serve as a forum for ongoing communication so that faculty doing collaborative learning techniques get together regularly (3)

- $\quad$ CSUDH should continue effective FLCs like this one (1)

SDE edited a little - do more "It takes time to formulate a program and effective groups, As soon as the program gains momentum, it stops; thus, inhibiting the effectiveness of the current program and future progress. There needs to be a structure in place, headed by the university, for those teachers/faculty interested in pursuing. Having a community to discuss ideas, collaborate on techniques, conference proposals, papers, etc. is valuable not only for the teacher but for the university and ultimately what we are all here to do: Improve the learning of our students (1)

- Extend FLC for 3 consecutive semesters - spring preparation, fall implementation, spring evaluation

- $\quad$ More training in HIP (4)

- Additional feedback and continued learning (1)

- Learn how to integrate into traditional and online classes (1)

On-campus Forum for Faculty to Share these Experiences with Faculty Colleagues

- Having workshops or informal sessions for faculty to meet and share their experiences with rest of faculty (5)

Fund Faculty Attendance/Presenting at Conferences Addressing Collaborative Learning

- $\quad$ Fund faculty attendance at conferences addressing collaborative learning techniques (currently not funded) (3)

Require Departmental Support for Interdisciplinary Faculty Collaboration

- Departmental support for interdisciplinary collaboration (6)

Institutional Access to Research Literature/Knowledge Base

- Continue studying the literature on effectiveness of different collaborative teaching techniques (1)

- Make sure that the library has key literature (articles, texts, journal subscriptions) that comprise the knowledge base of collaborative learning techniques (3)

Create Standardized Evaluation Protocol/Create Large-scale, Longitudinal Database

- $\quad$ Establish a centralized, standardized evaluation protocol for all faculty to use in undergraduate and graduate, online, hybrid and traditional classes and require its use so that the university can create a large-scale, longitudinal database to evaluate the effectiveness of HIPs and whether they increase retention and graduation rates. 
pedagogical knowledge and skills to improve the quality of their teaching.

The participating faculty enjoyed this experience and credited the FLC with helping them prepare to successfully implement CLTs in their classes. Among those who implemented CTLs, half trusted findings their evaluations that suggested that this work improved student learning and critical thinking. The others, who had also generated findings indicating that the CLTs were successful, were skeptical due to their use of simplified evaluations that used small samples and subjective measures.

\section{Prerequisites and Recommendations for Successful Inter-Professional Collaboration}

The four prerequisites of successful inter-professional collaboration incentives, willingness, ability and capacity - provide a framework for evaluating the process and outcome of this FLC. For each prerequisite, the indicators mentioned by FLC participants are identified first, followed by those provided by the administration.

Incentives. FLC faculty noted four incentives that prompted their participation. These included: (1) the opportunity to acquire new knowledge; (2) the chance to develop professional relationships with campus colleagues from different disciplines and professions; (3) snacks; and (4) the $\$ 1,000$ cash payment received for completing FLC work.

The administration allocated $\$ 90,000$ for cash payments to the 90 faculty who participated in all ten FLCs in Spring 2015; it is likely that the initiative itself required additional funds. A new, annual, campus-based conference about innovative teaching, inviting presentation proposals from all campus faculty was inaugurated. Breakfast and lunch were served to all attendees. Two CLT FLC faculty presented research about their work at this conference.

Willingness. FLC faculty demonstrated a willingness to trust each other, which seems to have overcome each participant's unshared but surprisingly strong skepticism and ambivalence about both the FLC process and CLT effectiveness at the start. Members appeared to have quickly recognized that everyone there shared their values about teaching excellence and practiced ongoing evaluating and improving their instruction. This made this FLC a "safe" place for the work and also a "safe" place to figure out how to work collaboratively. The mutual respect and shared values were probably responsible for helping the group limp through the first three confusing sessions to reach success in the last two.

The FLC initiative conveyed the administration's trust in its faculty, too. It suggested that administrators believed that the quality of faculty instruction mattered and that faculty deserved support in this work. In some ways, the FLC initiative was a gift to faculty willing and eager for opportunities to improve their teaching at a campus increasingly emphasizing the need for scholarly research.

Along with the funding incentive, these are important considerations for the faculty, particularly for the time in which this transpired. Faculty at the 23 CSU campuses were working without a contract since July 2015. Protracted negotiations over salaries and benefits initiated in 2014 were heading toward a historic, week-long 
strike in April 2016 that administrators did not support and that was narrowly averted by a last-minute agreement that was ratified by faculty vote (California Faculty Association, 2016). Despite recent state budget improvements, the average annual salary for faculty at public institutes of higher education was recently estimated to be $\$ 78,874$, compared to $\$ 90,206$ for those at private institutions (Arntz, Clery \& Miller, 2017, p. 1).

The Faculty Development Center also illustrates the administration's willingness. Providing pre-training to co-facilitators, setting the session meeting schedule, scheduling rooms for FLCs to meet, and paying modest stipends directly to faculty are more examples of this prerequisite from the administration.

Ability. In the first three FLC sessions, it was increasingly obvious that the FLC faculty lacked the ability to work collaboratively to learn and master how to implement CLTs. Instead, the serendipitous discovery and use of a journal article with concrete suggestions for FLC session activities spurred the FLC's subsequent success in the last two FLC sessions.

The distribution of the CTL book by the administration provided what the faculty needed to learn about CLTs and how to implement them. The two-hour pretraining for the co-facilitators, though, did not appear to prepare these FLC participants to guide the group in working collaboratively.

Capacity. Participating FLC faculty capacity was evident in attendance. With one exception (a co-facilitator was presenting a paper at a teaching conference), the FLC participants came to campus on a Friday (when they did not have classes or meetings), arriving on time to begin the work by 9 am and attending every session. The administration established the FLC initiative and set up mechanisms and arrangements necessary for them to operate, representing capacity. Like this FLC itself, these were short-term.

\section{Recommendations for the Future}

The six-month long CLT FLC appears to have been successful, although the faculty's work was never evaluated to determine whether and how well CLTs increased retention and graduation rates. Additional indicators of successful interprofessional collaboration are suggested as factors that could have expanded this FLC's accomplishments and might improve future such initiatives at this and other campuses.

Missing indicators of incentives. To sustain and extend the success of the CLT FLC, more meetings could have been scheduled over the summer or in the fall 2015 semester. This would have served as a powerful incentive for these faculty to continue working together, since they themselves requested that the Faculty Development Center extend the FLC into the summer and fall semesters. Absent the FLC structure and support, faculty lacked a venue to discuss and assist each other in implementing the CLTs, which may have improved the overall quality of their work. It could have also generated a cadre of faculty with inter-professional collaborative experience and accomplishments with two high impact practices. In turn, these faculty could informally mentor and co-facilitate new faculty FLCs to expand the reach of this work. Continuing this FLC would also serve as an incentive for these faculty to strengthen and expand the knowledge and skills they acquired about CLTs. And of course, 
granting workload releases for participating in the FLC would have been an even bigger incentive (and cost more).

Publishing proceedings of the innovative teaching conference could serve as another, even if this was limited to posting presenter PowerPoints on the website of the Faculty Development Center. These missing incentives squandered the good faith of the participating faculty. Their absence suggests that the administration had no interest in institutionalizing or sustaining the work that the CLT FLC faculty had successfully completed together. Other campuses considering introducing FLCs should plan long-term in order to identify and provide as many incentives as possible if sustainability is desired.

Missing indicators of willingness. The Administration's willingness was focused exclusively on getting the FLCs running and completed. Neither the Provost's Office nor the Faculty Development Center contacted the FLC faculty to find out if they had implemented the CLTs as planned.

Nor, for the matter, did the Faculty Development Center's Director inform the participating faculty what, if anything, was done with the pre-/post-test survey that they were asked to fill out. The questions on the survey, which were the same both times it was administered, asked respondents to rank collegiality within their department or program and to share their views of faculty collaborations within departments and across campus. There were no questions about high impact practices or their relationship to increasing student retention or graduate rates.

The absence of these willingness indictors indicates that the administration was not interested in maintaining ongoing support of the spring 2015 CLT FLC. Again, it appears that sustainability and continuity were not goals, either.

Additional indicators of willingness could be grafted into existing campus activities. For example, the President and Provost sponsor and attend a few annual campus events to honor and award certificates to select faculty for a range of accomplishments (including an annual teaching excellence award, an annual research award, and awards for 5-year, 10-year, and longer years of campus employment). Adding an award or two for FLC faculty would add prestige to participating and raise campus awareness that the administration valued the work of faculty participating in initiatives intended to increase retention and graduation rates.

Missing indicators of ability. Access to research studies investigating the effectiveness of high impact practices in general and FLCs and CLTs in particular was limited at the CSUDH library. Requests to expand its subscriptions to include academic journals addressing FLCs and CLTs were ignored. The campus still does not have access to Learning Communities Journal edited by Kuh, as well as other key sources. This can be addressed in new FLC initiatives and should be fulfilled by other campuses considering the adoption of high impact practices so that they can evaluate whether they work for their students.

Missing indicators of capacity. To improve the success of the FLC, administrative commitment to ongoing support is needed. The CLT FLC faculty lacked time to design evaluation protocols for their work, a capacity that could have been provided by the administration and one recommended for future initiatives. Too, participating faculty should be invited to participate in planning how to evaluate their work as well help to design how to assess the effectiveness of the entire FLC initiative, 
another indicator of capacity that was missing here. At CSUDH, this was moot since there did not appear to be any administrative or institutional attempt to find out if these FLCs increased retention and graduation rates, a strange oversight at an institute of higher education. Publishing the conference proceedings, which can be done easily and inexpensively by posting the PowerPoints on the Faculty Development Center's website, is another missing capacity indicator.

\section{Study Limitations}

This qualitative study is, by its very nature, subjective; a CLT FLC participant interpreted these findings. It is possible that this study does not accurately represent the views of some or all of the CLT FLC participants (or the administrators involved in this initiative). However, participating CLT FLC faculty received an earlier version of this manuscript that they were asked to review, and no questions or challenges were raised to the contents.

One significant limitation to this study is institutional. In Spring 2016, the Provost, who had introduced a series of broad-based initiatives, including the FLCs, to increase student retention and graduation rates left, CSUDH. An interim Provost filled the position until a new Provost joined the faculty in June 2017. The Director of the Faculty Development Center was on sabbatical in AY2016-2017 and stepped down to return to full-time faculty status upon her return. The Acting Director for AY2016-2017 turned down the option of continuing in that position, which remains vacant. A national search to fill the position is in process.

The future of the FLC initiative at CSUDH is unknown. ${ }^{4}$ It was introduced without any long-range planning or attention to sustainability and absent any evaluation considerations. And even though the CLT FLC addressed here appears to have been successful, there is no way to tell if the FLC initiative, or the other broadbased initiatives introduced at the same, actually increased retention and graduation rates. Any future endeavor of this nature must make sure to address these factors in order to avoid wasting time and money. With attention to the full range of indicators of collaborative success, high impact practices in general, as well as FLCs and CLTs, can make a difference in undergraduate education at CSUDH and beyond.

4 The FLC initiative at CSUDH was restarted in spring 2017, on a much smaller scale. Each semester, three or four new, one-semester FLCs have been created with one exception: In spring 2017, a new iteration of the collaborative teaching initiatives FLC with this author and three new faculty colleagues met and received permission to continue this work through fall 2017 and spring 2018. This new FLC is currently completing a pilot study evaluating a standardized assessment of collaborative teaching initiatives for all types of courses, including those offered to graduate and undergraduate students and those offered online and in traditional classroom settings. If shown to be effective, this assessment tool may be used to generate a longitudinal database of these efforts across the entire campus that can, eventually, be used to test whether and how this particular high impact practice contributes to increasing graduation and retention rates. 


\section{References}

Addis, E. A., Quardokus, J. M., Bassham, D. C., Becraft, P. W, Boury, N., Coffman, C. R., ... Powell-Coffman, J. A.(2013). Implementing pedagogical change in introductory biology courses through the use of faculty learning communities. Journal of College Science Teaching, 43(2), 2229.

Ahmad, S. (April 2016). Rats invade York College. Clarion: Newspaper of the Professional Staff Congress, City University of New York. Retrieved from http://psccuny.org/clarion/april-2016/rats-invadeyork-college

Arntz, M., Clery, S., \& Miller, A. (2017). The slow road to salary gains. NEA Higher Education Advocate, 33(2), 1-39. Retrieved from

http://www.nea.org/assets/docs/HE/NEA _HigherEd_Advocate_SalaryReview2017. pdf

Baker, L. A., Chakraverty, D., Columbus, L., Feig, A. L., Jenks, W. S., Pilarz, M., ... Weseman, J. L. (2014). Cottrell Scholars collaborative new faculty workshop: Professional development for new chemistry faculty and initial assessment of efficacy. Journal of Chemical Education, 91, 1874-1881.

Barkley, E. F., Major, C. H., \& Cross, K. P. (2014). Collaborative learning techniques: $A$ handbook for college faculty ( $2^{\text {nd }}$ ed.). San Francisco, CA: John Wiley \& Sons, Inc./Jossey-Bass.

Beach, A. L., \& Cox, M. D. (2009). The impact of faculty learning communities on teaching and learning. Learning Communities Journal, 1(1), 3-10.
Beery, T. A., Beischel, K., Churchill, J., Dempsey, A., Hart, J., Losekamp, T., ... Pettigrew, A. (2011). Creating a regional disciplinary SoTL faculty community of practice. Learning Communities Journal, 3, 3-20.

Bishop-Clark, C. U., Dietz, B., \& Cox, M. D. (2014). Developing the scholarship of teaching and learning using faculty and professional learning communities. Learning Communities Journal, 7, 25-42.

Blaisdell, M., \& Cox, M. D. (2004). Midcareer and senior faculty earning communities: Learning throughout faculty careers. New Directions for Teaching and Learning, 2004(97), 137-148.

Bonet, G., \& Walters, B. R. (2016). Highimpact practices: Student engagement and retention. The College Student, 15(2), 224235. Retrieved from

http://academicworks.cuny.edu/cgi/viewc ontent.cgi? article $=1101 \&$ context=kb_pubs

Boose, D. L., \& Hutchings, P. (2016). The scholarship of teaching and learning as a subversive activity. Teaching and Learning, 4(1), 1-12.

doi: 10.20343/teachlearninqu.4.1.6

Brownell, J. E., \& Swaner, L. E. (2010). Five high-impact practices: Research on learning outcomes, completion, and quality. Washington, DC: American Association of Colleges \& Universities. 
California Faculty Association. (2016, May 24). California State University Board Trustees to ratify agreement with California Faculty Association. Sacramento, CA: California Faculty Association. Retrieved from https://www.calfac.org/item/californiastate-university-board-trustees-ratifyagreement-california-facultyassociation

California State University, Office of the Chancellor. (2012). The California State University's Affordable Learning Solutions Initiative: Report to the State Legislature, Joint Legislative Audit Committee. Long Beach, California: CSU Office of the Chancellor. Retrieved from

http://als.csuprojects.org/uploads/c8/ad/ c8ad254a5be3c552723335f7c39adb47/CS U-ALS-report-to-JLAC-2-2012-v1.2.pdf

Desrochers, C. G. (2011). Faculty learning communities as catalysts for implementing successful small-group learning. In J. Cooper \& P. Robinson (Eds.), Small group learning in higher education: Research and practice (2 ${ }^{\text {nd }}$ Ed., pp. 1-17). Stillwater, OK: New Forums Press.

Einbinder, S. D., Robertson, P. J., Garcia, A., Vuckovic, G., \& Patti, R. J. (2000). Interorganizational collaboration in social service organizations: A study of the prerequisites to success. Journal of Children E Poverty, 6(2), 119-140.

Furco, A., \& Moely, B. E. (2012). Using learning communities to build faculty support for pedagogical innovation: A multi-campus study. The Journal of Higher Education, 38(1), 128-153.
Ganesh, C., \& Smith, J. A. (2017). Using multiple high-impact practices to improve student learning in an undergraduate health science program. Journal of the Scholarship of Teaching and Learning, 17(2), 74-84.

doi: 10.104434josotl.v17i2.20852

Gray, P. J. (2000). The role of assessment in initiating and sustaining learning communities. Assessment Update: Progress, Trends and Practices in Higher Education, 12(2), 6-7.

Hegler, K. L. (2004). Assessing learning communities. Assessment Update: Progress, Trends and Practices in Higher Education, 16(6), 1-8.

Hershberg, A., Cesarini, P., Chao, J., Mara, A., Rajaei, H., \& Madigan, D. (2005). Balancing acts: Tenure-track faculty in learning communities. Academe, 91(4), 44-48.

Hilliard, A. T. (2012). Practices and value of a professional learning community in higher education. Contemporary Issues in Education Research, 5(2), 71-73.

How to recruit faculty to learning communities. (2006). Student Affairs Leader, 34(5), 1-2.

Hsieh, H. F. \& Shannon, S. E. (2005). Three approaches to qualitative content analysis. Qualitative Health Research, 15(9), 1277-1288. doi: $10.1177 / 1049732305276687$

Hubball, H., Clarke, A., \& Beach, A. L. (Spring 2004). Assessing faculty learning communities. New Directions for Teaching and Learning, 97, 87-100. 
Jackson, D. L., Stebleton, M. J., \& Laanan, F. S. (2013). The experience of community college faculty involved in a learning community program. Community College Review, 4(1), 3-19.

Jessup-Anger, J. E. (2015). Theoretical foundations of learning communities. New Directions for Students Services, 2015(149), 17-27. doi 10.1002/ss.20114

Kilgo, C. A., Sheets, J. K. E., \& Pascarella, E. T. (2015). The link between highimpact practices and student learning: Some longitudinal evidence. Higher Education, 69, 509-525,

doi: 10.1007/s10734-014-8788-z

Kuh, G. D. (Ed.). (2008). High-impact educational practices: What they are, who has access to them, and why they matter. Washington, DC: Association of American Colleges and Universities. Retrieved from

https://www.aacu.org/leap/hips

Lincoln, Y. S., \& Guba, E. G. (1985). Naturalistic inquiry. Newbury Park, CA: Sage Publications.
Look to midcareer faculty for learning communities. (April 2006). Academic Leader, 22(4), 3.

Ortquist-Ahrens, L., \& Torosyan, R. (2009). The role of the facilitator in faculty learning communities: Paving the way for growth, productivity, and collegiality. Learning Communities Journal, 1(1), 29-62.

Robinson, C. F. (2014). Trouble recruiting top faculty? Promote collaboration. Chronicle of Higher Education, 60(28), 20.

Sicat, B. L., Kreutzer, K. O., Gary, J., Ivey, C. K., Marlowe, E. P., Pellegrini, J. M., ... Simons, D. F. (2014). Faculty development: A collaboration among health sciences schools to enhance faculty development in teaching. American Journal of Pharmaceutical Education, 78(8), 1-5.

Sirum, K. L., Madigan, D., \& Kilonsky, D. J. (Jan/Feb 2009). Enabling a culture of change: A life science faculty learning community promotes scientific teaching. Journal of College Science Teaching, 38(3), 38-44.

Susan D. Einbinder, MS, PhD, received her BA from Barnard College and her MS and PhD from Columbia University. She is an Associate Professor and founding faculty member of the graduate MSW Program at California State University Dominguez Hills in Carson, California, where she has been appointed a Faculty Fellow at the campus Faculty Learning Community in Fall 2018. Her interdisciplinary research explores how social policies can ameliorate poverty; translating Critical Race Theory into social work practices; expanding the use of research methods throughout social work education and professional practices; and evaluating different approaches to improve teaching excellence. 